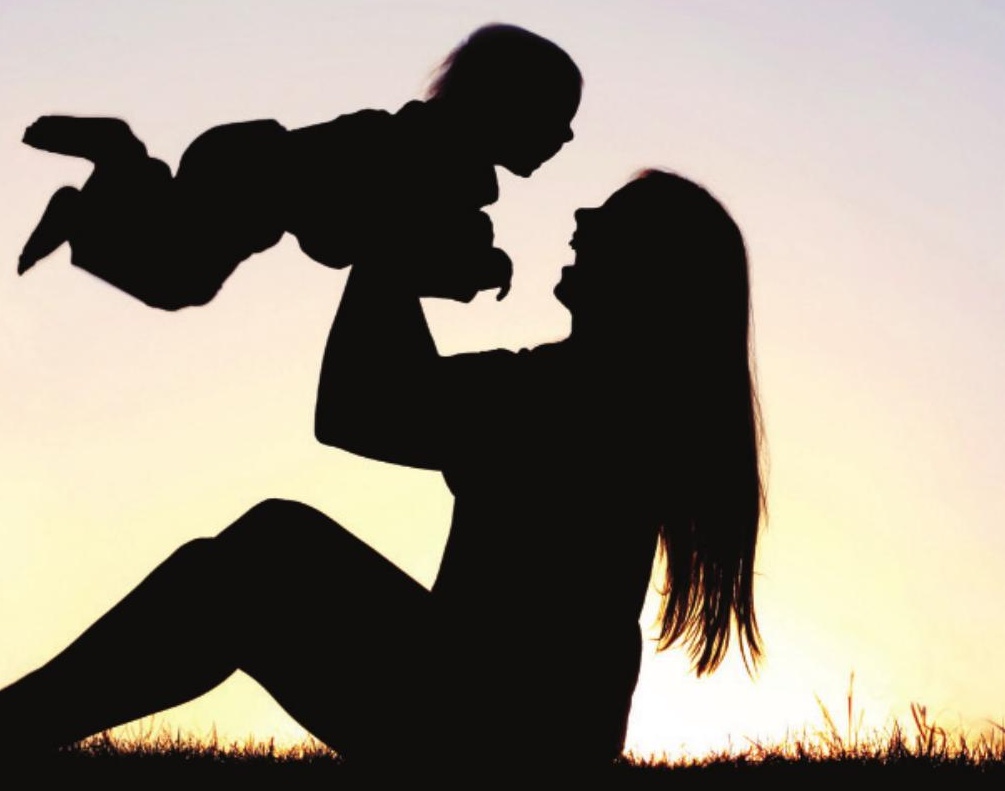

Maternity leave policies

Trade-offs between labour market demands and health benefits for children

Lucy Strang, Miriam Broeks 
For more information on this publication, visit www.rand.org/t/RR1734

Published by the RAND Corporation, Santa Monica, Calif., and Cambridge, UK

(C) European Union, 2016

Reproduction is authorised provided the source is acknowledged.

RAND $^{\circ}$ is a registered trademark.

RAND Europe is a not-for-profit organisation whose mission is to help improve policy and decisionmaking through research and analysis. RAND's publications do not necessarily reflect the opinions of its research clients and sponsors.

Support RAND

Make a tax-deductible charitable contribution at

www.rand.org/giving/contribute

www.rand.org

www.rand.org/randeurope 


\section{Preface}

This policy brief was developed by RAND Europe, which in 2011 was commissioned by the European Commission's Directorate-General for Employment, Social Affairs and Inclusion to provide content and technical support for the European Alliance for Families platform, which became the European Platform for Investing in Children (EPIC) in 2013.

The European Platform for Investing in Children (EPIC) was set up to explore demographic and economic challenges in the EU from a child and family-focused perspective. Its purpose is to share the best of policymaking for children and their families, and to foster cooperation and mutual learning in the field. This is achieved through information provided on the EPIC website, which enables policymakers from the Member States to search evidence-based child-focused practices from around the EU and to share knowledge about practices that are being developed, and also by bringing together government, civil society and European Union representatives for seminars and workshops to exchange ideas and learn from each other.

RAND Europe is an independent not-for-profit policy research organisation that aims to improve policy and decisionmaking in the public interest, through research and analysis. RAND Europe's clients include European governments, institutions, non-governmental organisations and firms with a need for rigorous, independent, multidisciplinary analysis.

The document is designed to provide insights into issues of interest to policymakers and practitioners. It has been reviewed by one of the EPIC external experts in child and family policy, and internally, following RAND's quality assurance processes.

The opinions expressed do not necessarily reflect the position of the European Commission. 


\section{Table of contents}

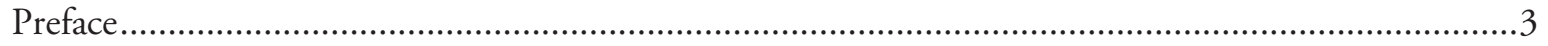

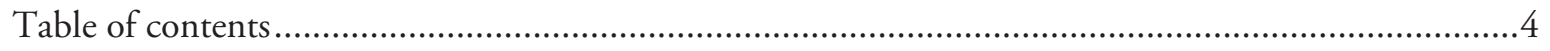

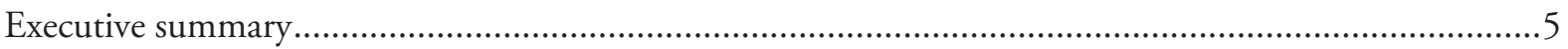

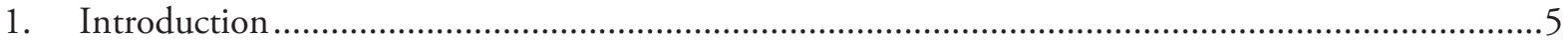

2. Maternity leave policies and their impact on breastfeeding practices and infants' health..................6

2.1. Existing maternity leave policies in Europe ..........................................................................6

2.2. An overview of the evidence on the health benefits of breastfeeding .......................................10

2.3. Linking the characteristics of leave policies with their impact on breastfeeding rates ...............11

3. Extended maternity leave policies and trade-offs for labour market demands ..................................13

3.1. Research findings on economic factors of extended maternity leave .......................................13

3.2. An examination of the labour market trade-offs for extended maternity leave for women.........14

3.3. Extending maternity leave also has economic implications for companies ................................15

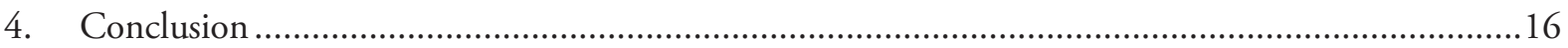

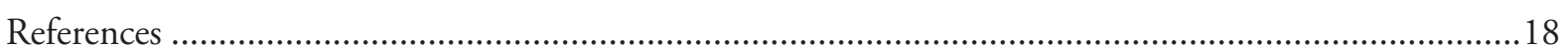




\title{
Maternity leave policies: trade-offs between labour market demands and health benefits for children
}

\author{
Lucy Strang and Miriam Broeks, RAND Europe
}

\section{Executive summary}

- In recent years, many EU states have made changes to the design of maternity leave provision, reflecting research findings that long periods of leave can have negative effects on women's labour market attachment and career advancements. At the same time, the World Health Organisation recommends that babies should be exclusively breastfed up to the age of 6 months to provide them with the necessary nutrition for healthy growth and development. Returning to work early can be a factor preventing exclusive breastfeeding, and therefore potentially carry negative health impacts for babies.

- The aim of this brief is to examine the relationship between maternity leave provision and the health benefits for children. We examine maternity leave provision across EU countries and its potential impact on the breastfeeding of very young babies (up to 6 months of age).

- We also consider the economic aspects of a potential extension of maternity leave provision to 6 months, such as costs to businesses, effects on the female labour market attachment, and wider consequences (benefits and costs) for individuals, families, employers and the wider society.

\section{Introduction}

Maternity leave is defined as the pre- and post-natal break from work taken by mothers of newly-born children (Eurofound 2015a). The design of maternity leave policies across the majority of European countries is shaped by a traditional concept of leave intended only for women, linked to pregnancy, childbirth and the first months of motherhood. In this way it is treated as a health and welfare measure (INLPR 2015). However, over recent years many EU countries have made changes to the design of maternity leave provision through the introduction of, and changes to, the parental and paternity leave schemes, and by allowing mothers to transfer part of the maternity leave periods to the other parent. These policy developments reflect calls for greater gender equality in the workforce and a more equal share of childcare responsibilities. Labour market demands and benefits for women, however, may be counter to the health benefits for children. The World Health Organisation (WHO) recommends exclusive breastfeeding up to 6 months of age (WHO 2016a), since exclusive breastfeeding provides babies with the perfect nutrition for healthy growth and brain development, and protection from various health threats (Agostini et al. 2009; Chung et al. 2007; Horta et al. 2007). Returning to work early can be a factor preventing exclusive breastfeeding, and therefore, have potentially negative health impacts for babies. In order to encourage more women to breastfeed, WHO promotes policies that enable women to exclusively breastfeed, e.g. by enacting six months (26 weeks) mandatory paid maternity leave, and policies that encourage women to breastfeed in the workplace and in public (WHO 2011).

The aim of this brief is to examine the tension existing between the inclusion of women in the labour market and supporting breastfeeding practices in order to maximise health benefits for infants. First, maternity leave provision and breastfeeding rates across European countries will be examined, as well as the potential impact of maternity leave provision on the breastfeeding of very young babies (up to six 
months of age). In the second section, the economic factors relating to the potential extension of maternity leave provision to six months, such as effects on the female labour market attachment and future employability, costs to businesses, and wider consequences (benefits and costs) for individuals, employers and the wider society, are discussed. This brief concludes with recommendations for policymakers who are seeking to resolve the tension between the demands on mothers to engage in the labour market and the resulting impact on children's health and development.

\section{Maternity leave policies and their impact on breastfeeding practices and infants' health}

\subsection{Existing maternity leave policies in Europe}

To begin exploring the existing tension between including women in the labour market and supporting breastfeeding practices, this section provides an overview of the current maternity leave policies across European countries. ${ }^{1}$ Under the EU Maternity Leave Directive (92/85/EEC), women have the right to a minimum of 14 weeks (3 months) of maternity leave, of which at least two weeks are compulsory, and can be allocated before and/or after giving birth. While this directive serves as guidance for member states, there is still significant variation in the way that maternity leave policy is structured across EU countries. This variation can be differentiated across five areas: duration of leave, whether it is mandatory or not, degree of compensation, the agency in charge of providing it, and the level of flexibility allowed in the mode of uptake.

Duration and legal status: In terms of length of leave, there is variation not only in terms of the number of weeks available, but also in whether the leave is mandatory, non-mandatory, or a combination thereof. There is also variation across countries in the length and type of both pre-natal and post-natal maternity leave; however, for brevity, only post-natal maternity leave is examined here. Moreover, in this brief we primarily focus on maternity leave policies for employed mothers.

Figure 1 presents the varying duration of mandatory and non-mandatory post-natal maternity leave across EU-28 countries. There are nine EU countries that only provide mandatory leave, ranging from 6 to 13 weeks in length, and six countries that only provide non-mandatory leave, ranging between 8 and 52 weeks. The shortest identifiable total leave length is given by Spain ( 6 mandatory leave weeks) while the longest is given by Bulgaria (52 non-mandatory weeks). There is also a varied mix of mandatory and nonmandatory post-natal maternity leave provision, with countries providing different combined proportions of each. Poland stands out by being the country that provides the longest number of mandatory leave weeks (15).

\footnotetext{
${ }^{1}$ Paternity and parental leave policies are beyond the scope of this brief.
} 
Figure 1 - Number of post-natal maternity leave weeks in EU-28 countries

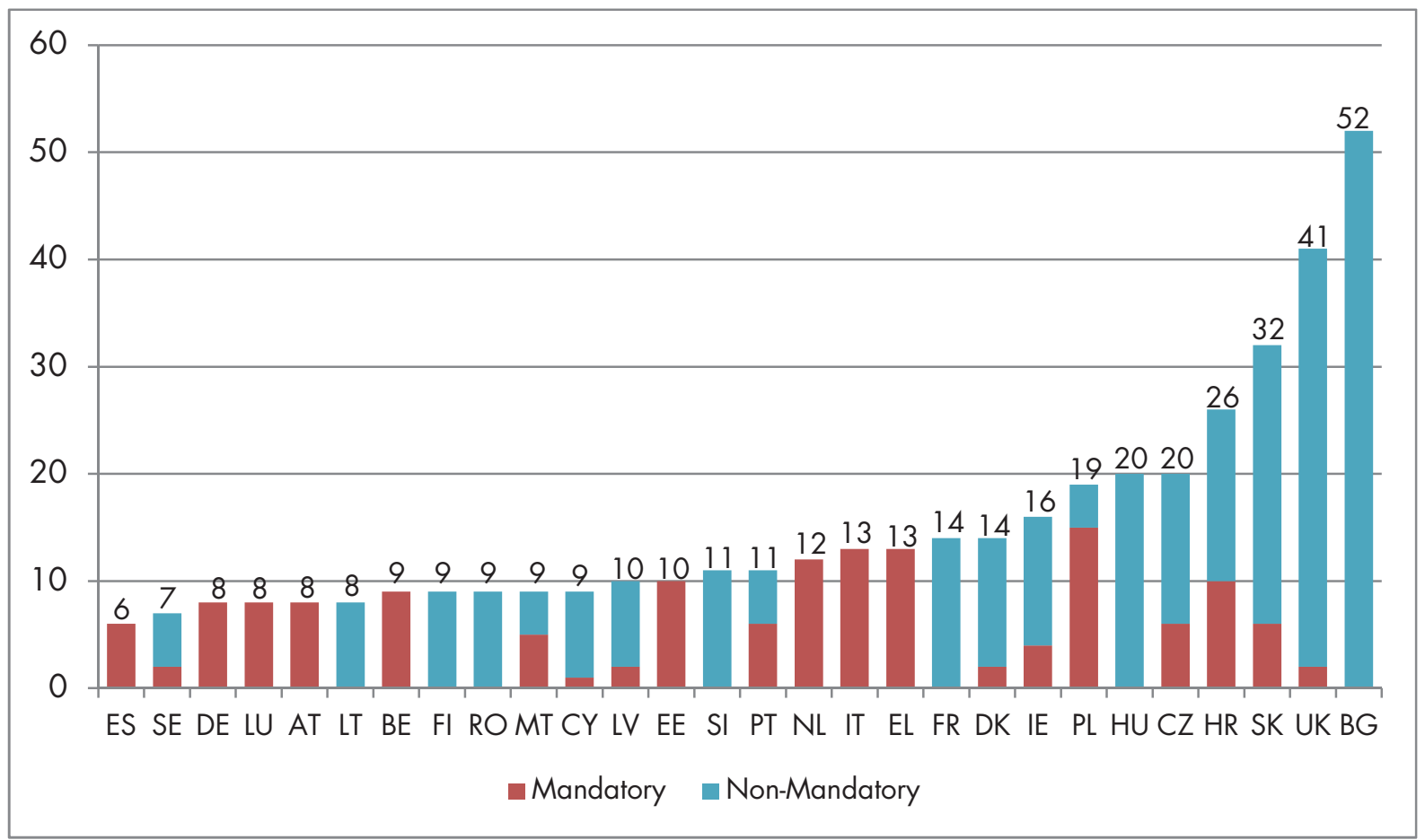

Source: European Parliament (2014).

Values presented in graph are for total (mandatory and non-mandatory) number of post-natal maternity leave weeks.

Abbreviations: AT - Austria; BE - Belgium; BG - Bulgaria; CY - Cyprus; CZ - Czech Republic; DE - Germany; DK - Denmark; EE - Estonia; EL - Greece; ES - Spain; FI - Finland; FR - France; HR - Croatia; HU - Hungary; IE - Ireland; IT - Italy; LT - Lithuania; LU - Luxembourg; LV Latvia; MT - Malta; NL - Netherlands; PL - Poland; PT - Portugal; RO - Romania; SE - Sweden; SI - Slovenia; SK - Slovakia; UK - United Kingdom.

Degree of compensation: There is also significant variation across countries in terms of the level of remuneration women can receive while on maternity leave, and whether this is fixed for the entire duration of leave or whether it changes with time. In some countries, mothers are entitled to receive $100 \%$ of their usual earnings throughout the entire leave period (see Table 1 for examples). In other cases, such as in Poland and Portugal, there is variation, with mothers receiving between $80 \%$ and $100 \%$ of their usual earnings, depending on the length of leave. Within the group of countries with maternity allowances that decrease with the duration of leave, Ireland is unique: it does not provide pay in accordance with a woman's previous wage, but rather based on a flat rate mutually agreed between the employer and employee. Alternatively, maternity leave can be unpaid.

Eligibility criteria: In some countries, receiving maternity leave compensation is dependent on certain eligibility criteria, such as the length of time worked or the contributions paid to social security prior to taking maternity leave (Eurofound 2015a). For example, in Ireland from 2014 on, employed women are eligible to claim maternity leave when they have made at least 39 weeks of social security contributions in the 12 months prior to beginning maternity leave or since they started working. By comparison, in 
Poland, all pregnant employees are entitled to take any form ${ }^{2}$ of maternity leave, regardless of length of service (European Commission 2013).

Entity paying for maternity leave: There is also variation regarding who is responsible for maternity leave pay, whether it is employers, a public entity or a mix of both. As Table 1 shows, in the vast majority of EU-28 countries maternity leave pay is sourced from social security funds or, speaking more generally, a public authority. In Denmark, Malta, Romania and the UK, maternity leave is paid by the employer. However, in all these cases except for Malta, employers are later reimbursed by the government. In Austria, Greece and Germany, maternity leave pay is sourced from a combination of employer and governmental funds.

Flexibility: Flexibility in the use of maternity leave policies relates to the level of choice mothers have in deciding when to start taking the leave and how much of the leave they want to take (INLPR 2015). Table 1 also shows that there is variation in the degree of flexibility with which maternity leave can be taken. In nine of the listed countries there is no flexibility; however, in the majority of countries at least some degree of flexibility is possible. In countries listed as having 'some' flexibility, mothers may receive additional leave time for multiple births or births with medical complications. In the case of Cyprus, the Czech Republic, Croatia, Spain, Poland, and the UK, part of the leave can be transferred to the father. Furthermore, Poland and Spain have high flexibility since in addition to the above described possibilities, part of the maternity leave period can be taken as part-time or the length of leave can be extended. In the case of Greece, flexibility depends on working in either the private or public sector, with no flexibility in the former and some (additional leave time in case of multiple or complicated births) in the latter. Finally, in the case of Sweden, while mothers are obliged to take two weeks of leave before or after delivery, they can choose whether or not to receive part of the parental leave insurance benefit during this leave time (INLPR 2015).

\footnotetext{
${ }^{2}$ Mandatory or additional leave.
} 
RAND Policy Brief

Table 1 - Maternity leave pay characteristics in EU-28 countries

\begin{tabular}{|c|c|c|c|c|c|c|c|c|c|c|c|}
\hline \multirow[b]{3}{*}{ 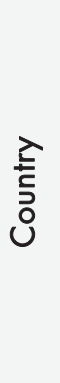 } & \multicolumn{7}{|c|}{ Maternity allowance rate } & \multicolumn{3}{|c|}{ Maternity allowance paid by } & \multirow[b]{3}{*}{ Flexibility } \\
\hline & \multicolumn{4}{|c|}{ For entire duration } & \multicolumn{3}{|c|}{$\begin{array}{l}\text { Decreasing fraction over } \\
\text { the duration }\end{array}$} & \multirow[b]{2}{*}{ Employer } & \multirow{2}{*}{$\begin{array}{l}\text { Social } \\
\text { Security } \\
\text { (Public } \\
\text { authority } \\
\text { or 'Social } \\
\text { Security') }\end{array}$} & \multirow[b]{2}{*}{ Mix } & \\
\hline & $\begin{array}{c}100 \\
\%\end{array}$ & $\begin{array}{c}100 \% \text { or } \\
80 \% \\
\text { depending } \\
\text { on length } \\
\text { of leave }\end{array}$ & $\begin{array}{l}8 \\
0- \\
9 \\
0 \\
\%\end{array}$ & $\begin{array}{c}65- \\
74 \\
\%\end{array}$ & $\begin{array}{l}\text { Flat } \\
\text { rate / } \\
\text { unpai } \\
d\end{array}$ & $\begin{array}{c}80- \\
90 \% / \\
\text { flat } \\
\text { rate }\end{array}$ & $\begin{array}{c}\text { Mixe } \\
d \\
(75- \\
90 \%)\end{array}$ & & & & \\
\hline AT & $\mathrm{X}$ & & & & & & & & & $\bullet$ & Some \\
\hline $\mathrm{BE}$ & & & & & & $\mathrm{x}$ & & & 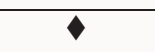 & & Some \\
\hline BG & & & $x$ & & & & & & $\diamond$ & & - \\
\hline $\mathrm{CY}$ & & $\mathrm{X}$ & & & & & & & 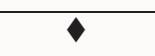 & & Some \\
\hline $\mathrm{CZ}$ & & & & $x$ & & & & & $\diamond$ & & Some \\
\hline $\mathrm{DE}$ & $\mathrm{x}$ & & & & & & & & & $\bullet$ & None \\
\hline DK & $\mathrm{X}$ & & & & & & & $\checkmark$ & & & None \\
\hline $\mathrm{EE}$ & $\mathrm{X}$ & & & & & & & & $\bullet$ & & None \\
\hline EL & & $x$ & & & & & & & & $\checkmark$ & None/Some \\
\hline ES & $\mathrm{X}$ & & & & & & & & $\checkmark$ & & High \\
\hline $\mathrm{FI}$ & & & & & & & $\mathrm{X}$ & & 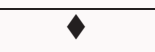 & & None \\
\hline FR & $\mathrm{x}$ & & & & & & & & $\diamond$ & & Some \\
\hline HR & $\mathrm{X}$ & & & & & & & & 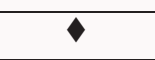 & & Some \\
\hline $\mathrm{HU}$ & & & & $\mathrm{X}$ & & & & & $\diamond$ & & None \\
\hline IE & & & & & $x$ & & & & $\diamond$ & & None \\
\hline IT & & & $X$ & & & & & & 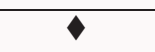 & & Some \\
\hline$\overline{L T}$ & $X$ & & & & & & & & 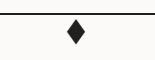 & & Some \\
\hline LU & $\mathrm{x}$ & & & & & & & & 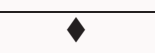 & & Some \\
\hline LV & & & $x$ & & & & & & 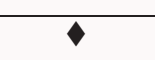 & & - \\
\hline MT & & & $X$ & & & & & $\downarrow$ & & & None \\
\hline$\overline{\mathrm{NL}}$ & $X$ & & & & & & & & $\nabla$ & & None \\
\hline $\mathrm{PL}$ & & $\mathrm{x}$ & & & & & & & $\diamond$ & & High \\
\hline PT & & $X$ & & & & & & & $\downarrow$ & & - \\
\hline RO & & & $X$ & & & & & 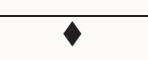 & & & - \\
\hline SE & & & & & & $x$ & & & $\downarrow$ & & Some \\
\hline $\mathrm{SI}$ & $\bar{X}$ & & & & & & & & $\downarrow$ & & None \\
\hline SK & & & & $X$ & & & & & $\diamond$ & & Some \\
\hline UK & & & & & & $x$ & & $\checkmark$ & & & Some* \\
\hline
\end{tabular}

Sources: European Commission (2013); International Network on Leave Policies and Research [INLPR] (2015); *UK Government (2016). 


\subsection{An overview of the evidence on the health benefits of breastfeeding}

A main objective of the Maternity Leave Directive (92/85/EEC) is to safeguard the health of pregnant workers and workers who have recently given birth or are breastfeeding, as well as that of their infants. Indeed, there is significant evidence showing a positive relationship between breastfeeding duration and infant health. On this basis, international organisations are seeking to adapt regulations on maternity leave. In 2008, the European Commission proposed extending mandatory leave from two to six weeks and non-mandatory leave provision from 14 to 18 weeks to improve the protection of pregnant workers and new parents (Eurofound 2015b). However, this proposal was withdrawn in July 2015. Furthermore, WHO recommends six months of exclusive breastfeeding and continued complementary breastfeeding up to two years of age, as this was found to be most beneficial for children's early development (WHO 2016a). Given the increasing emphasis being put on breastfeeding, this section outlines evidence on breastfeeding health benefits for children and mothers.

Breastfeeding health benefits for infants: Many studies have found that breastfeeding is beneficial for the health of young infants. Infants who are breastfed have a reduced risk of suffering gastrointestinal problems, various types of infections, obesity and Type 1 and 2 diabetes, among other reduced risks (Agostini et al. 2009). Chung and colleagues (2007) found that breastfeeding for at least three months reduced the risk of Type 1 diabetes in childhood, compared to breastfeeding for a shorter period. The benefits of breastfeeding are further enhanced when this is practised exclusively (i.e. feeding infants no solids or liquids besides human milk). Anderson et al.'s meta-analysis examined the effects of breastfeeding on neurodevelopment and concluded that longer periods of breastfeeding resulted in increased infant cognitive development when compared to formula-fed children (Anderson et al. 1999). Moreover, a 2002 study on the optimal duration of exclusive breastfeeding found that infants in both developed and developing countries who are breastfed exclusively for six months are less prone to suffering gastrointestinal infections than those who are mixed-breastfed from the age of three or four months (Kramer \& Kakuma 2002). Similar results were obtained by the Dutch Agency for Healthcare Research and Quality (AHRQ), which found that exclusive breastfeeding helped reduce the risk of acute otitis media significantly more than exclusive formula-feeding did. Greater gains were also observed when exclusive breastfeeding was extended to six months compared to three (Van Rossum et al. 2006). These findings suggest that the length (six months or more) and mode of breastfeeding (exclusive or not) are crucial in increasing the benefits of breastfeeding.

Long-term breastfeeding health benefits: Evidence also suggests that breastfeeding can have positive effects at later stages in life. A 2007 WHO study found that individuals who were breastfed as infants had reduced chances of being overweight as adolescents (Horta et al. 2007). Similarly, another meta-analysis found that levels of total blood cholesterol (TC) differed with age. While at younger ages little difference was found between the TC levels of breast- and formula-fed children, in adulthood, those who were breastfed had lower TC levels (Owen et al. 2002).

Breastfeeding health benefits for mothers: An aspect often overlooked in the discussion about the health benefits of breastfeeding are the benefits it brings to mothers. Breastfeeding is complex and is related to much more than simply nutrition (Godfrey \& Lawrence 2010). Staehelin and colleagues (2007) found a positive association between the length of maternity leave, the duration of breastfeeding and the mother's 
mental health. Studies have also found that breastfeeding reduces the likelihood of breast cancer (CGHFBC 2002), ovarian cancer and Type 2 diabetes (Stuebe 2009).

While there is significant evidence supporting the positive effects of breastfeeding on health, this discussion cannot ignore some caveats which influence breastfeeding practice. For example, socioeconomic status has been found to influence breastfeeding initiation: women from higher-income families and with higher levels of education are more likely to breastfeed (Heck et al. 2006; Gibbs \& Forste 2014). Similarly, mothers with higher socioeconomic statuses tend to have healthier diets during and after pregnancy than their counterparts with lower socioeconomic statuses (Larranaga et al. 2013). These factors will likely account for the long-lasting health benefits of breastfeeding.

Overall, evidence shows that the longer children are breastfed, in particular when it is exclusive and for at least six months, the greater the health benefits that are obtained. Therefore, encouraging breastfeeding is in the interest of the greater society, particularly in Europe, which records the lowest rates of breastfeeding in the world (Cattaneo 2004). To address this issue and to promote breastfeeding, structural and societal barriers which inhibit it need to be tackled. Furthermore, increasing breastfeeding rates can be seen as a human capital investment: increased breastfeeding rates can contribute to a healthier workforce overall, in the short-term with healthier mothers returning to work, and in the long-term with healthier future workers.

\subsection{Linking the characteristics of leave policies with their impact on breastfeeding rates}

A number of factors have been found to determine the initiation of breastfeeding: cultural or societal influences, such as breastfeeding being an accepted norm or not (Staehelin et al. 2007), and institutional or regulatory factors, i.e. hospital assistance, workplace support and parental leave policy, which influence if, how and for how long a child is breastfed (Galtry 2003). This section focuses on regulatory or maternity policy factors, since a positive relationship between longer maternity leave and increased breastfeeding duration has been identified (Hawkins et al. 2007). To exemplify this, the breastfeeding rates and leave policies of some EU countries are compared and briefly discussed.

Breastfeeding and leave length: A study with a cohort of Irish mothers found that those who were breastfeeding when their infants were two, six or 12 months old reported taking longer maternity leave than mothers who were not breastfeeding their infants at those ages (Smith et al. 2015). Similarly, Hawkins and colleagues (2007) found that the longer mothers delayed returning to work after giving birth, the more likely they were to breastfeed for at least four months. Having to return to work for financial reasons and using informal day care arrangements, rather than they themselves or their partners caring for their infants were other factors found to limit breastfeeding. In addition, exclusive breastfeeding significantly declines after returning to work and mothers begin complementing it with formula or replacing it all together (Fischer \& Olson 2014).

Breastfeeding and mothers' employment status: Differences in breastfeeding practice are also observed between mothers who work part-time and those who work full-time. A study with a Scottish cohort found that non-working and part-time working mothers were less likely to stop breastfeeding sooner than full-time employees after controlling for age, education and social class (Skafida 2012). This shows that the time at which breastfeeding is stopped and that at which mothers return to work are closely linked, 
given the difficulty in combining the two. Furthermore, Kimbro (2006) found that mothers who work full-time before giving birth are less likely to initiate breastfeeding to begin with, compared to part-time or non-working mothers.

\section{Figure 2 - Breastfeeding rates (\%) in EU-28 countries}

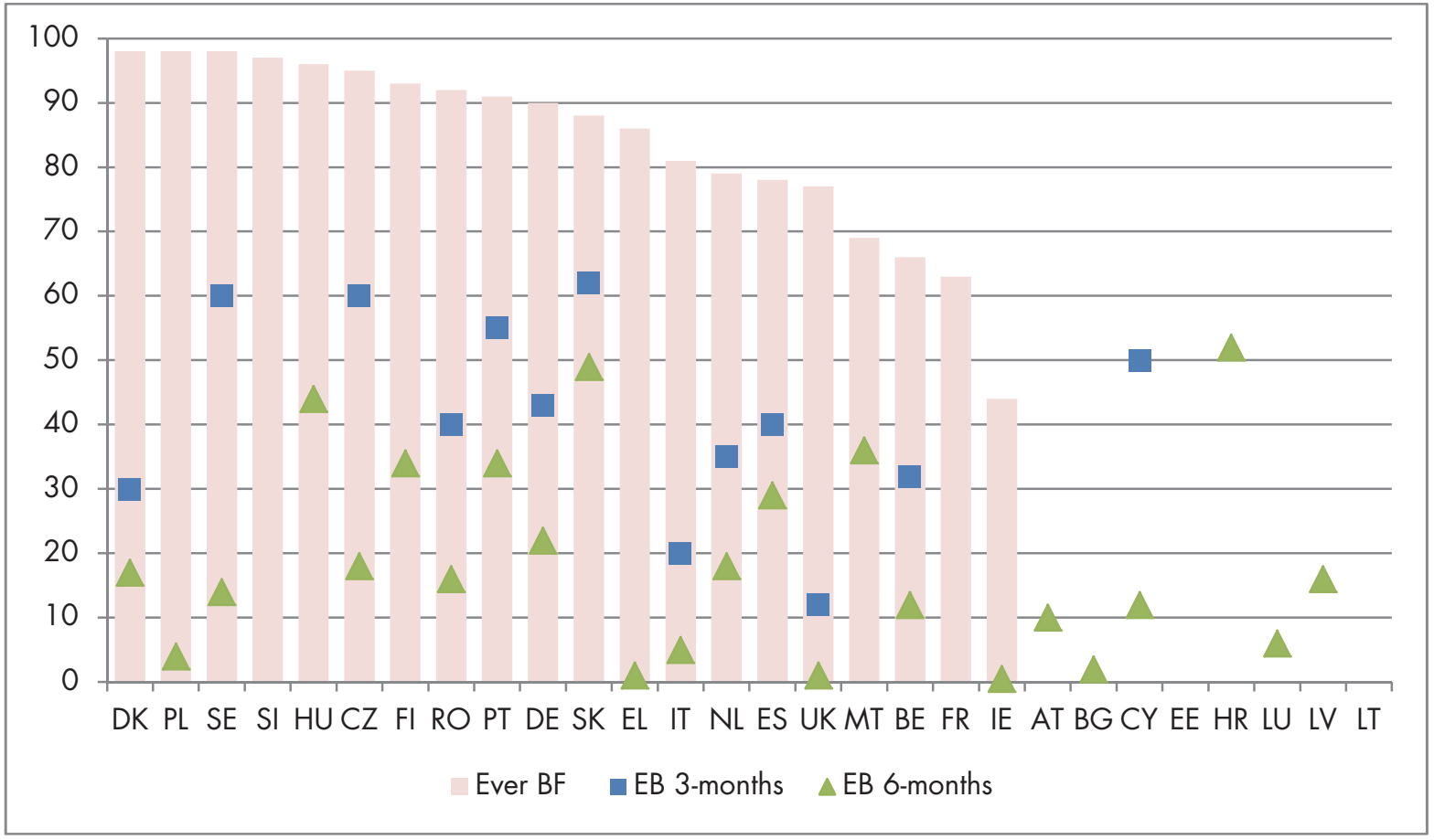

No available data for Lithuania.

Ever BF: Proportion of children who are ever breastfed in 2005, equivalent to initiation rates; EB: Exclusive breastfeeding.

Sources: Values for 'Ever BF' and 'EB 3-months' taken from OECD (2009); 'EB 6-months' values taken from WHO (2016b), except for Ireland taken from Tarrant and Kearney (2008), and Finland taken from OECD (2009) value corresponding to EB at 4 months.

Given the positive link between length of maternity leave and breastfeeding practice it is worth examining European breastfeeding rates. However, this data is often inaccurate and incomplete for many countries, making it difficult to provide a holistic picture of breastfeeding rates. Figure 2 compiles the latest available figures from different sources.

Figure 2 shows that, as in the case of maternity leave provision, there is also significant variation across countries on the proportions of children who are ever breastfed. Scandinavian and Eastern European countries report the highest proportions of children who are ever breastfed. However, in all cases, exclusive breastfeeding reduces significantly at six months. Two countries that stand out are Croatia and Ireland. Croatia reports the highest exclusive breastfeeding rate (52\%) at six months compared to all other EU-28 countries. In contrast, Ireland not only exhibits the lowest initiation rate at 44\%, but also the lowest rate of exclusive breastfeeding at six months, with less than $1 \%$ of infants at this age being exclusively breastfed. In regards to maternity leave policies (Figure 1 and Table 1), Croatia provides for 10 weeks of mandatory leave plus 16 non-mandatory weeks remunerated at $100 \%$ of usual earnings and allowing for some flexibility. In contrast, while Ireland is not among the shortest provisions of mandatory or non-mandatory leave, four and 12 weeks respectively, it is the only EU country where all instances of 
maternity leave are remunerated at a flat rate or not at all. In the Irish case, mothers are likely to return to work early due to economic reasons, which as Hawkins and colleagues (2007) found is an important factor inhibiting continued breastfeeding. This suggests that not only is the duration of leave important, but so too are the conditions of the leave provision, which make its uptake attractive or not. These and other implications of taking maternity leave are linked with the key tension this policy brief is examining: extending maternity leave, for the benefit of longer breastfeeding, may be detrimental to the mother's professional career, while at the same time, an early return to work is seen as a factor preventing exclusive breastfeeding (Cattaneo 2004).

\section{Extended maternity leave policies and trade-offs for labour market demands}

\subsection{Research findings on economic factors of extended maternity leave}

This section aims to examine the evidence on the economic factors involved for women and businesses in extending mandatory maternity leave to six months, particularly in terms of women's rate of participation in the labour market, the effect of longer periods of leave on human capital, mothers' future employability after taking leave and costs for business. However, it is important to note that the existing evidence on this subject is generally weak. As noted above, the characteristics of leave programmes vary widely across and within countries, for example in terms of the level of benefits accrued during leave, the flexibility allowed in the mode of uptake and relevant eligibility criteria for mothers taking leave, such as their length of service.

In interpreting research findings on the economic factors to be considered in extending maternity leave, we must acknowledge that the way that leave entitlements work in practice has a heavy influence on their take-up by mothers and the ensuing economic impact of maternity leave. In particular, the variety of programmes in place across the EU, and the differences in individual companies' leave policies within countries, makes it difficult to generalise findings on the economic impacts of extended leave (OECD 1995). Furthermore, research on maternity leave programmes, especially of more than three months, tends to focus on the impact on child health rather than on economic effects, and so the evidence base on the latter is relatively slight. Longitudinal studies, in which the same subjects are studied over long periods of time, could be particularly illuminating here, particularly as researchers would be able to control for sample selection bias, unobserved heterogeneity and cohort effects (Gangl \& Ziefle 2009). While numerous such studies have examined the long-term health impacts of breastfeeding, few have focused on the economic impact of extended breastfeeding and maternity leave on the individual or national level. Furthermore, it is important to note the limits of government policy in influencing maternal and indeed parental behaviour: societal norms relating to the roles of mothers and fathers in childcare continue to exert a strong influence on the behaviour of working parents. These norms vary across countries and change within them over time (Cameron \& Moss 2007). 


\subsection{An examination of the labour market trade-offs for extended maternity leave for women}

Extending maternity leave coverage to six months would have profound implications for women's participation in the labour market, businesses and society more broadly, something which must be considered in any policy discussion on the subject. In particular, the impact on the rate at which women engage in the labour market, their professional development, future employability and wages, and on gender relations at home and in the workforce has been the focus of a number of research studies.

Labour market participation: Research has suggested that the rate at which women engage in the labour market is generally impacted upon by maternity leave provisions both before and after pregnancy. Before, the availability of maternity leave increases the supply of prospective mothers to the workforce, while after, it provides continuing labour market engagement (Ruhm 1998). Using data from 16 European countries over the period 1969-1988, Ruhm conducted an analysis of the economic impact of parental leave on women. The author reported that, overall, maternity leave has a positive effect on women's employment rates, which increases with longer periods away from work: 1-14 weeks resulted in a $2.7 \%$ increase in the predicted female employment-to-participation ratio; 14-26 weeks led to a 4.3\% increase; and over 26 weeks resulted in a 4.6\% increase. The study also found indications that short leave entitlements lead to increased working hours upon mothers' return to work, although it did not find evidence of this effect for longer periods of leave. Indeed, 30 weeks of leave has also been found to have a positive effect on the number of hours worked by mothers returning to work (Ruhm 1996). This might be particularly important for mothers in countries where part-time work has a lasting and negative impact on wages and career opportunities (Akgunduz \& Plantenga 2013). On the other hand, analysis by Schonberg and Ludsteck (2007) of the expansion of protected maternity leave from two to six months in Germany in 1979 found that while it induced more women to delay their return to work following childbirth, there was little evidence that this change brought about any long-term effect on mothers' participation in the labour market. These conclusions led the authors to suggest that the expansion did not promote mothers' employment continuity.

Other research has suggested that 30 weeks of paid leave has the most positive effect on participation in the labour market (Akgunduz \& Plantenga 2013). By contrast, when leave periods are longer than six months, there may be an adverse effect on the rates of mothers returning to work (Pronzato 2009). On the other hand, research has suggested that where mothers are offered a very short leave provision, there is a high risk that they will leave the labour force entirely, or at least transition to part-time work (Keck \& Saraceno 2013).

This may also result in the depreciation of human capital - defined as the experience, abilities, knowledge and training gathered and possessed by individuals - as, if women's employment opportunities diminish with time spent away from work, mothers may become increasingly less likely to return to work the more time they spend away from work (Schonberg \& Ludsteck 2007). Depreciation of human capital may be felt more intensely by women in skilled professions, rather than in more routine professions such as manufacturing (Akgunduz \& Plantenga 2013). However, a mother's decision to return to work is strongly influenced by her individual circumstances, including her work experience and whether she worked during her pregnancy, the health of the child, and whether it is her first child or a later birth: mothers typically return to work sooner after their first child (Hofferth \& Curtin 2003). 
Future employability: Time out of work may have implications for mothers' future employability. Research suggests 30 weeks of leave shows the best results in terms of participation in the labour market, although 20 weeks of leave is seen as ideal for minimising the negative effects on high-skill wages and occupational segregation (certain professions becoming entrenched as 'women's jobs'), while still gaining the bulk of the participation effect seen with 30 weeks of leave. Anything beyond 30 weeks was perceived to have minimal impact on participation and potentially lead to decreased wages and increased occupational segregation (Grimshaw \& Rubery 2015).

Wages: Ruhm's (1996) analysis of the economic consequences of parental leave mandates in Europe found indications that short periods of paid leave do not reduce predicted wages for mothers, while 14-26 weeks is associated with a relatively small wage differential of $-1.5 \%$, increasing to $-2.9 \%$ for more than 26 weeks. Analysis by Schonberg and Ludsteck (2007) found that expanding leave from two to six months lowered post-birth wages for mothers, even eight years after the birth. They attributed this to mothers losing more and accumulating less human capital during their leave period. On the other hand, employers may choose to invest in their qualified female employees if they expect them to return to work after leave, which increases labour productivity and women's relative earnings (Thevenon \& Solaz 2013). However, others have found little evidence of this in practice (Schonberg \& Ludsteck 2007).

Gender roles: There are also competing theories on the effect that extended maternity leave would have on gender equality. For example, if a six-month period of leave is put in place primarily on the grounds of the impact of breastfeeding on child health and development, the leave may be seen as primarily pertaining to women. However, this potentially weakens mothers' position in the workforce (Gangl \& Ziefle 2009). If equality in the home and at work is to be achieved, parental leave must be distributed between the parents in heterosexual two parent families, so as to avoiding further entrenching traditional roles (Galtry \& Callister 2005). On the other hand, where maternity leave is paid, women may continue to make a financial contribution to the household, rather than taking unpaid leave or having to resign, thereby resisting movement into regressive gender roles (Haas 2008).

Commentators have also noted that changes in traditional gender roles through extended paid maternity leave may extend beyond the family and the individual to the workplace and society at large. For example, some have argued that if leave entitlements foster continuous female participation in the labour market, there may be a growing acceptance from families and employers of both the place of women in the labour market, and their right to paid maternity leave. Social interaction may then produce a knock-on effect as more women feel they can enter the labour market, invest in a career before having children, take maternity leave and return to work (Gustafsson \& Kenjoh 2007).

\subsection{Extending maternity leave also has economic implications for companies}

Existing research on the financial costs to businesses in extending maternity leave to six months suggests that such a scheme might generate costs that female workers may directly or indirectly pay for. For example, extending maternity leave can mean a potential loss of productivity, although this depends on a number of factors: whether a shorter period of leave would induce the mother to return to work early rather than move into part-time work or give up work entirely, and whether her role might be filled by 
another person (Akgunduz \& Plantenga 2013). The impact on productivity could be felt beyond the individual and employer, by the broader economy.

A company's productivity losses may be remedied by hiring replacement personnel to take on the role of the employee on maternity leave. However, companies face training and replacement costs for staff on leave, as well as the depreciation of the human capital of their employee, which increases with leave length. These costs can be substantial in high-skill sectors, especially if availability is low and training is expensive to provide. However, in sectors such as manufacturing, which favour temporary contracts for staff, these costs may be lower (Akgunduz \& Plantenga 2013). Ruhm (1998) also reports that extended periods of leave may impose other burdens on businesses, including the challenges imposed by scheduling replacement workers, especially in countries where there are restrictions on the use of temporary fixedterm contracts. However, Akgunduz and Plantenga (2013) note that the use of temporary contracts and the availability of temporary agency staff have increased across Europe, which may result in lower replacement costs for employers. In seeking to further reduce leave expenses, employers could pass on costs to women through lower wages in a competitive labour market or through statistical discrimination against women in hiring and promotion decisions, particularly if similarly qualified male workers are available (Gangl \& Ziefle 2009).

Employers may also seek to keep women in jobs where time off has a limited impact or where it is relatively easy to replace them (Thevenon \& Solaz 2013). However, the authors note that it is difficult to draw conclusions with any certainty as to what the overall effect of maternity leave is on employer actions. Similarly, studies have suggested that employers may find women self-selecting into jobs where extended leave is a more straight-forward proposition, leading to occupational silos where women are overrepresented (Pronzato 2009).

\section{Conclusion}

This brief outlined the varying current maternity leave provisions and breastfeeding rates across Europe, and examined evidence on the effects of the length of maternity leave policies on both breastfeeding practices and mothers' labour market participation. Research in this field suggests that increasing mandatory maternity leave to six months poses potential trade-offs between improving infants' health while potentially impacting negatively on mothers' career progression and imposing increased costs to business. Given the implications of maternity leave policies on breastfeeding rates and consequently infants' health, female participation in the workforce, gender equity and the economic costs to mothers and companies, it is in the interest of wider society to respond to and manage this tension and preserve both breastfeeding and labour market participation as far as possible.

Therefore, policymakers designing maternity leave policies should not solely regard them as health and welfare measures, but should consider the wider economic implications. The examined evidence shows that it is not only the length of maternity leave that has an impact on breastfeeding rates, but also the level of remuneration, with higher pay resulting in a higher likelihood of leave uptake and a longer duration of leave, which is positive for breastfeeding. Although more knowledge is needed on this, available evidence suggests that six months of maternity leave strikes the right balance in terms of mothers' participation in 
the labour market, with longer leave resulting in decreased wages and occupational segregation after return.

Harmonising European maternity leave policies to adopt six months of mandatory maternity leave provision is likely to be a complex and long process, given the significant variation in policies across countries. In the first instance, more research needs to be conducted on the question of the economic impact of extended maternity leave on women, families, business and society more broadly. Informed by a stronger evidence base, policymakers should consider complementary programmes that will facilitate breastfeeding while women participate in the labour market, for example by promoting the implementation of company policies that encourage breastfeeding at work, such as providing day care facilities or breastfeeding rooms (Fein et al. 2008). In addition, protections should be put in place to ensure that the career progression of women is not negatively impacted by the extension of maternity leave, and neither female workers nor companies are forced to bear all the financial costs of creating such a scheme. These are some key policy questions to be considered to ease the tension between increasing maternity leave to benefit infants' and mothers' health, and the detrimental effects of longer work breaks to mothers' careers. 


\section{References}

Agostoni, C., C. Braegger, T. Decsi, S. Kolacek, B. Koletzko, K.F. Michaelsen, K. Fleischer, W. Mihatsch, L.A. Moreno, J. Puntis, R. Shamir, H. Szajewska, D. Turck, \& J. van Goudoever. 2009. 'Breast-feeding: A commentary by the ESPGHAN Committee on Nutrition.' Journal of pediatric gastroenterology and nutrition 49 (1): 112-125.

Akgunduz, Y. E. \& J. Plantenga. 2013. 'Labour market effects of parental leave in Europe.' Cambridge Journal of Economics 37: 845-862.

Anderson, J.W., B.M. Johnstone \& D.T. Remley. 1999. 'Breast-feeding and cognitive development: a meta-analysis.' The American Journal of Clinical Nutrition 70 (4): 525-535. As of 7 September 2016: http://ajcn.nutrition.org/content/70/4/525.full.pdf+html

Cameron, C. \& P. Moss. 2007. Care Work in Europe: Current Understandings and Future Directions. Routledge, London.

Cattaneo, A. 2004. Protection, promotion and support of breastfeeding in Europe: a blueprint for action. EU Project contract N. SPC, 2002359. Luxembourg: European Commission, Directorate Public Health and Risk Assessment. As of 7 September 2016:

http://ec.europa.eu/health/ph_projects/2002/promotion/fp_promotion_2002_frep_18_en.pdf

Chung, M., G. Raman, P. Chew, N. Magula, T. Trikalinos, \& J. Lau. 2007. 'Breastfeeding and maternal and infant health outcomes in developed countries.' Evidence Report/Technol Assessment 153: 1-186.

Collaborative Group on Hormonal Factors in Breast Cancer [CGHFBC]. 2002. 'Breast cancer and breastfeeding: collaborative reanalysis of individual data from 47 epidemiological studies in 30 countries, including 50302 women with breast cancer and 96973 women without the disease.' The Lancet 360 (9328): 187-195.

European Commission. 2013. Your social security rights in Poland. Luxembourg: Publications Office of the European Union. As of 7 September 2016:

http://ec.europa.eu/employment_social/empl_portal/SSRinEU/Your\%20social\%20security\%20rights \%20in\%20Poland_en.pdf

European Parliament. 2014. 'Maternity and paternity leave in the EU: At a glance.' As of 7 September 2016: http://www.europarl.europa.eu/RegData/etudes/ATAG/2014/545695/EPRS_ATA(2014)545695_R EV1_EN.pdf

Eurofound. 2015a. Maternity leave provisions in the EU Member States: Duration and allowances.

Luxembourg: Publications Office of the European Union. As of 7 September 2016: http://digitalcommons.ilr.cornell.edu/cgi/viewcontent.cgi?article=1471\&context=intl

. 2015b. 'Commission withdraws proposal to extend maternity leave, promising a fresh start Developments at EU level - Q2 2015.' Eurofound, 14 July. As of 7 September 2016: http://www.eurofound.europa.eu/observatories/eurwork/articles/working-conditions-law-andregulation/commission-withdraws-proposal-to-extend-maternity-leave-promising-a-fresh-startdevelopments-at-eu 
Fein, S.B., B. Mandal \& B.E. Roe. 2008. 'Success of Strategies for Combining Employment and Breastfeeding.' Pediatrics 122 (2): 56-62.

Fischer, T. P. \& B.H. Olson. 2014. 'A qualitative study to understand cultural factors affecting a mother's decision to breast or formula feed.' Journal of Human Lactation 30 (2): 209-216.

Galtry, J. \& P. Callister. 2005. 'Assessing the Optimal Length of Parental Leave for Child and Parental Well-Being.' Journal of Family Issues 26 (2): 219-246.

Galtry, J. 2003. 'The impact on breastfeeding of labour market policy and practice in Ireland, Sweden, and the USA.' Social science \& medicine 57 (1): 167-177.

Gangl, M. \& A. Ziefle. 2009. 'Motherhood, labor force behaviour, and women's careers: An empirical assessment of the wage penalty for motherhood in Britain, Germany, and the United States.' Demography 46 (2): 341-369.

Gibbs, B.G. \& R. Forste. 2014. 'Socioeconomic status, infant feeding practices and early childhood obesity.' Pediatric obesity 9 (2): 135-146.

Godfrey, J.R. \& R.A. Lawrence. 2010. 'Toward optimal health: the maternal benefits of breastfeeding.' Journal of Women's Health 19 (9): 1597-1602. As of 7 September 2016: http://online.liebertpub.com/doi/pdf/10.1089/jwh.2010.2290

Grimshaw, D. \& J. Rubery. 2015. 'The Motherhood Pay Gap: A review of the issues, theory and international evidence.' Geneva: International Labour Office.

Gustafsson, S. \& E. Kenjoh. 2007. 'Timing of Maternity.' In Social Policies, Labor Markets and Motherhood: A Comparative Analysis of European Countries, edited by D. Del Boca \& C. Wetzels, 182-224. Cambridge: Cambridge University Press.

Haas, L. 2008. 'Parental Leave and Gender Equality: Lessons from the European Union.' Review of Policy Research 20 (1): 89-114.

Hawkins, S. S., L.J. Griffiths \& C. Dezateux. 2007. 'The impact of maternal employment on breastfeeding duration in the UK Millennium Cohort Study.' Public Health Nutrition 10 (9): 891-896.

Heck, K.E., P. Braveman, C. Cubbin, G.F. Chávez, J.L. Kiely \& G.F. Chárez. 2006. 'Socioeconomic status and breastfeeding initiation among California mothers.' Public health reports 121 (1): 51-59.

Hofferth, S.L. \& S.C. Curtin. 2003. The Impact of Parental Leave on Maternal Return to Work after Childbirth in the United States. OECD Social, Employment and Migration Working Papers 7. Paris: OECD.

Horta, B.L., R. Bahl, J.C. Martines \& C.G. Victora. 2007. Evidence on the long-term effects of breastfeeding. Systematic reviews and meta-analyses. Geneva: World Health Organisation. As of 7 September 2016: http://www.who.int/maternal_child_adolescent/documents/9241595230/en/

International Network on Leave Policies and Research [INLPR]. 2015. 11th International Review of Leave Policies and Related Research 2015. Edited by Peter Moss. London: Institute of Education University of London. As of 7 September 2016:

http://www.leavenetwork.org/fileadmin/Leavenetwork/Annual_reviews/2015_full_review3_final_8jul y.pdf 
Keck, W. \& C. Saraceno. 2013. 'The impact of different social-policy frameworks on social inequalities among women in the European Union: The labour-market participation of mothers.' Social Politics: International Studies on Gender, State and Society 20 (3): 297-328.

Kimbro, R.T. 2006. 'On-the-job moms: work and breastfeeding initiation and duration for a sample of low-income women.' Maternal and Child Health Journal 10 (1): 19-26.

Kramer, M.S. \& R. Kakuma. 2002. 'Optimal duration of exclusive breastfeeding (Review).' Cochrane Database of Systematic Reviews 1: 11-12.

Larranaga, I., L. Santa-Marina, H. Begiristain, M. Machón, M. Vrijheid, M. Casas, A. Tardón, A. Fernández-Somoano, S. Llop, C.L. Rodriguez-Bernal \& M.F. Fernandez. 2013. 'Socio-economic inequalities in health, habits and self-care during pregnancy in Spain.' Maternal and Child Health Journal 17 (7): 1315-1324.

Organisation for Economic Co-operation and Development. 1995. Employment Outlook 1995. Paris: OECD. As of 7 September 2016: http://www.oecd.org/els/emp/2409893.pdf

2009. CO1.5: Breastfeeding rates. OECD Social Policy Division - Directorate of Employment, Labour and Social Affairs. As of 7 September 2016: https://www.oecd.org/els/family/43136964.pdf

Owen, C.G., P.H. Whincup, K. Odoki, J.A. Gilg, \& D.G. Cook. 2002. 'Infant feeding and blood cholesterol: a study in adolescents and a systematic review.' Pediatrics 110 (3): 597-608.

Pronzato, C.D. 2009. 'Return to work after childbirth: does parental leave matter in Europe?' Review of the Economics of the Household 7: 341-360.

Ruhm, C.J. 1996. 'The Economic Consequences of Parental Leave Mandates: Lessons from Europe.' NBER Working Paper 5688. Cambridge, Massachusetts: The National Bureau of Economic Research.

Ruhm, C.J. 1998). 'The Economic Consequences of Parental Leave Mandates: Lessons from Europe.' The Quarterly Journal of Economics 113 (1): 285-317.

Schonberg, U. \& J. Ludsteck. 2007. Maternity Leave Legislation, Female Labor Supply, and the Family Wage Gap. IZA DP No. 2699. Bonn: IZA.

Skafida, V. 2012. 'Juggling work and motherhood: the impact of employment and maternity leave on breastfeeding duration: a survival analysis on Growing Up in Scotland data.' Maternal and Child Health Journal 16 (2): 519-527.

Smith, H.A., J.O.B. Hourihane, L.C. Kenny, M. Kiely, D.M. Murray \& P. Leahy-Warren. 2015. 'Early life factors associated with the exclusivity and duration of breast feeding in an Irish birth cohort study.' Midwifery 31 (9): 904-911.

Staehelin, K., P.C. Bertea \& E.Z. Stutz. 2007. 'Length of maternity leave and health of mother and child-a review.' International Journal of Public Health 52 (4): 202-209. As of 7 September 2016: http://link.springer.com/article/10.1007/s00038-007-5122-1

Stuebe, A. 2009. 'The risks of not breastfeeding for mothers and infants.' Reviews in Obstetrics and Gynecology 2 (4): 222-231. 
Tarrant, R. \& J. Kearney. 2008. 'Breastfeeding practices in Ireland: a review.' Proceedings of the Nutrition Society 67 (4): 371-380.

Thevenon, O. \& A. Solaz. 2013. Labour Market Effects of Parental Leave Policies in OECD Countries. OECD Social, Employment and Migration Working Papers 141. Paris: OECD.

UK Government. 2016. 'Maternity pay and leave.' GOV.UK, 19 May. As of 7 September 2016: https://www.gov.uk/maternity-pay-leave

Van Rossum, C.T.M., F.L. Büchner, \& J. Hoekstra. 2006. Quantification of health effects of breastfeeding: Review of the literature and model simulation: RIVM report 350040001/2005. Bilthoven: RIVM.

World Health Organization. 2011. 'Exclusive breastfeeding for six months best for babies everywhere.' WHO.com/Media centre, 15 January. As of 7 September 2016:

http://www.who.int/mediacentre/news/statements/2011/breastfeeding_20110115/en/

2016a. 'Health topics: Breastfeeding.' WHO.com/Health topics. As of 7 September 2016: http://www.who.int/topics/breastfeeding/en/

. 2016b. 'Exclusive breastfeeding under 6 months: Data by country.' WHO.com/Global Health Observatory data repository. As of 7 September 2016:

http://apps.who.int/gho/data/view.main.NUT1730 